\section{Seasonal Variations in Bottom Water Temperatures and their Influence on Subaquatic Permafrost Thermal Regimes}

F. Miesner ${ }^{1}$, P. P. Overduin ${ }^{1}$, C. W. Stevens ${ }^{2}$
- Measured Temperature from 4 boreholes in the Mackenzie River Delta, NWT, Canada

- 1D thermal model forced with observed and parameterized bottom water temperature

- Model results agree well with each other

- To reduce mismatch with observed temperature fields below the seasonally-thawed layer, winter temperatures at $\mathrm{BH} 4$ needed to be $\approx 3^{\circ} \mathrm{C}$ lower

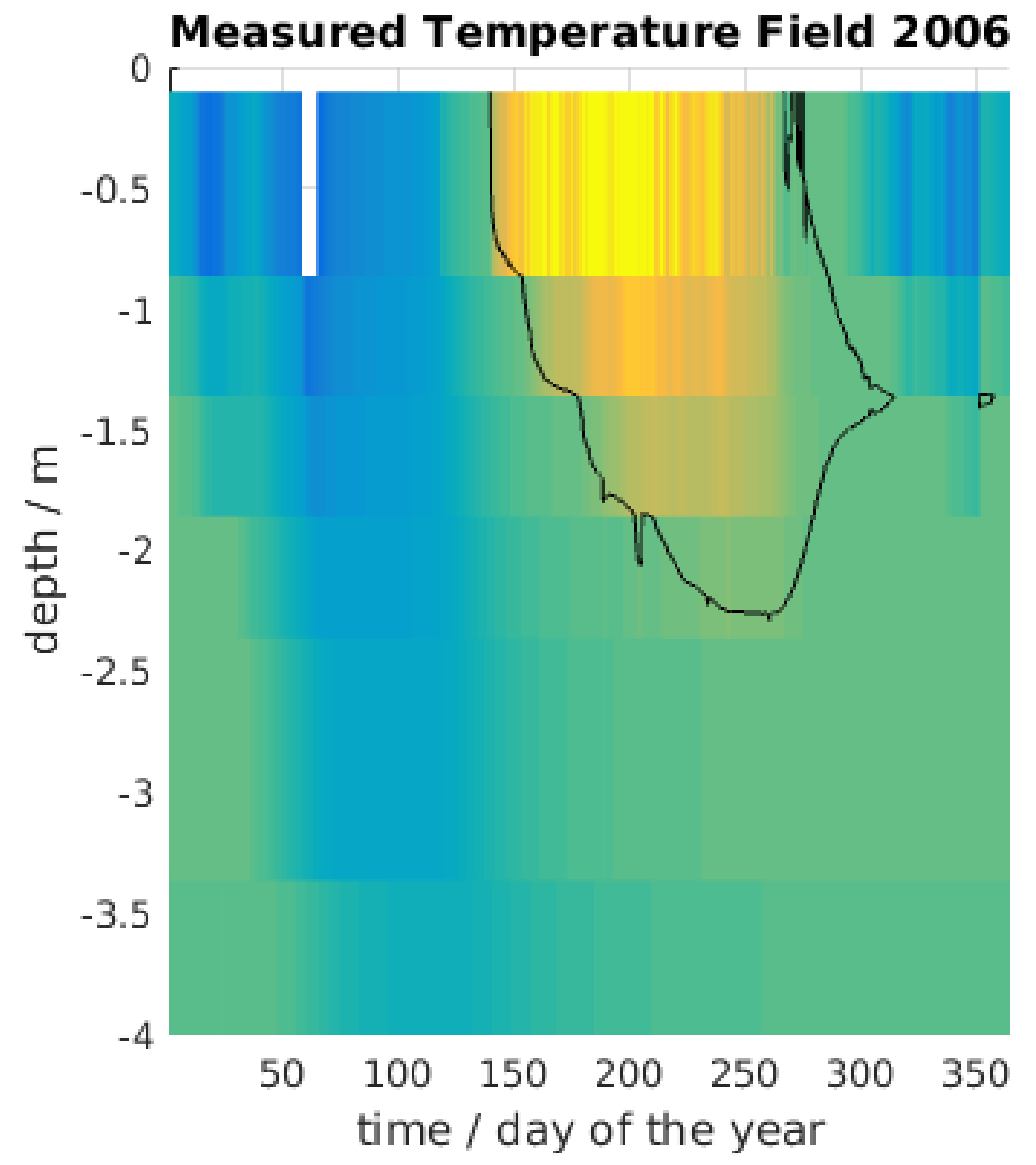

Temperature Field from Measured BWT
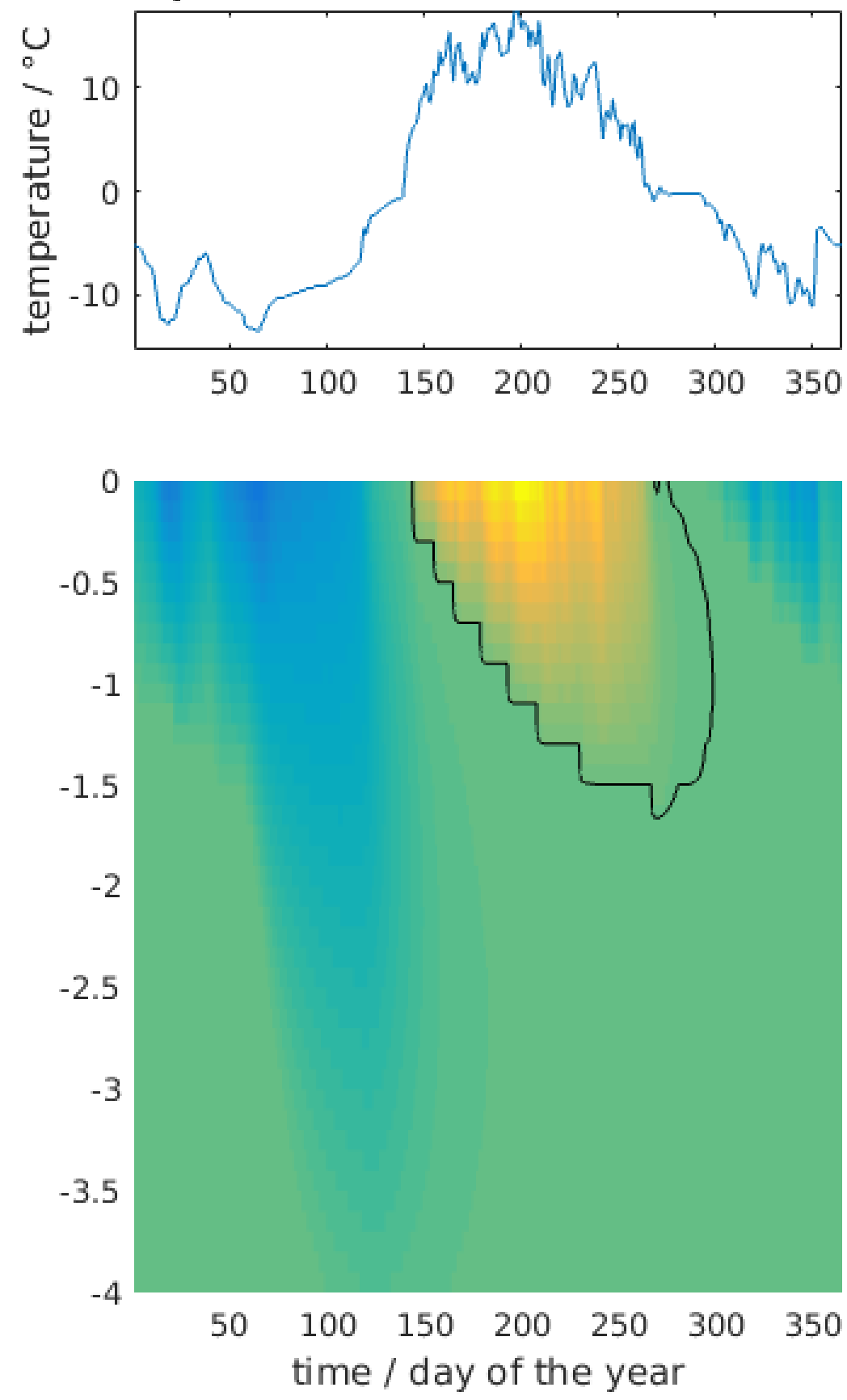

\section{Temperature Field from Parameterized BWT}
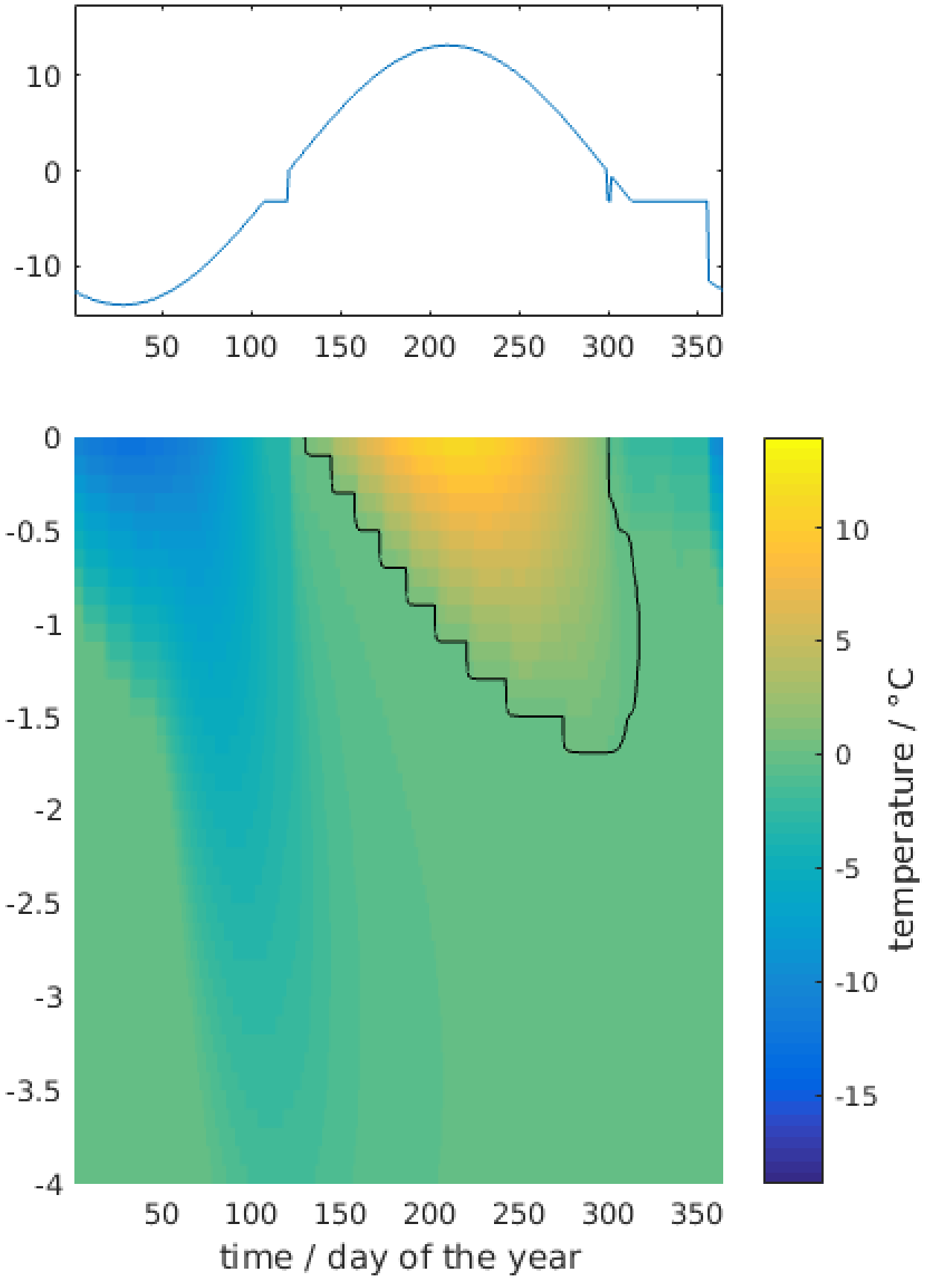